TITLE:

\title{
The relationship between rejection avoidance and altruism is moderated by social norms
}

$\operatorname{AUTHOR}(S)$ :

Kawamura, Yuta; Kusumi, Takashi

\section{CITATION:}

Kawamura, Yuta ... [et al]. The relationship between rejection avoidance and altruism is moderated by social norms. Personality and Individual Differences 2018, 129: 24-27

\section{ISSUE DATE:}

2018-07-15

URL:

http://hdl.handle.net/2433/254196

\section{RIGHT:}

(C) 2018. This manuscript version is made available under the CC-BY-NC-ND 4.0 license http://creativecommons.org/licenses/by-nc-nd/4.0/:; This is not the published version. Please cite only the published version.; この論文は出版社版でありません。引用の際には 出版社版をご確認ご利用ください。 
1

2

3

4

5

6

7

8

9

10

11

12

13

14

15

16

17

18 Correspondence should be addressed to:

19 Yuta Kawamura

20 Department of Education, Kyoto University

21 Yoshida-honmachi, Sakyo-ku, Kyoto 606-8501, Japan.

22

E-mail address: kawamura.yuta.83c@kyoto-u.ac.jp 


\section{Abstract}

Recently, the relationship between reputation and altruism has gained

26 significant attention. The present study examined whether the relationship between

27 rejection avoidance and altruism differs according to social norms. A total of 320

28 participants completed an online survey with questions concerning rejection avoidance and altruism in situations where either a prosocial or non-prosocial norm was present. As predicted, people with higher levels of rejection avoidance displayed less altruism only

31 in the context of non-prosocial norms. This result corresponds with previous evidence

32 that suggests that altruism can be evaluated negatively by others when it deviates from

33 social norms. These findings shed a new light on the relationship between reputation and 34 altruism.

Keywords: altruism; reputational concern; praise seeking; rejection avoidance; social norms; norm deviance 


\section{Introduction}

Individuals sometimes display altruism, which is the tendency to act on behalf of others, even at one's own expense (Fehr \& Fischbacher, 2003). Altruism has been shown to be affected by reputation (for a review, see Barclay, 2012). For example, people behave more altruistically when their behavior is being observed by others (Barclay \& Willer, 2007). Both laboratory (e.g., Andreoni \& Petrie, 2004; Barclay \& Willer, 2007) and field (e.g., Lacetera \& Macis, 2010) studies have repeatedly shown that situational factors that trigger concern for reputation promote altruism.

Based on these studies, it is probable that individual differences in the sensitivity to reputation (i.e., reputational concern) also relate positively to altruism; in other words, individuals with a high concern for their reputation would display more altruism. However, a recent study has shown that this relationship is not always positive. Kawamura and Kusumi (2018) examined how praise seeking, the tendency to seek a good reputation, and rejection avoidance, the tendency to avoid a bad reputation ( $\mathrm{Wu}$, Balliet, \& Van Lange, 2016), were related to altruism toward various recipients (i.e., family members, friends/acquaintances, and strangers). As predicted, individuals with higher levels of praise seeking displayed more altruism; however, individuals with higher levels of rejection avoidance displayed less altruism toward strangers.

Given that many studies have shown that reputational cues promote altruism, it is important to explore the contextual factors that negatively impact the relationship between reputational concerns and altruism. One possible explanation of this counterintuitive negative relationship is related to social norms. Sometimes altruism 
deviates from what most others do in a group (i.e., social norm). For example, when a group of co-workers are rushing because they are running late for a train, they may not help a stranger who appears to be searching for lost item at the station platform; in this situation, helping the person is regarded as a non-normative behavior in the group. Some studies suggest that altruism can be negatively evaluated when altruistic behavior is not normative. For example, Parks and Stone (2010) demonstrated that a person who excessively contributed more toward public goods than others was negatively evaluated by other group members. This finding is in line with Kawamura and Kusumi (2018) who measured altruism toward strangers, which is less normative compared to altruism toward more familiar recipients. Taken together these studies suggests that, when altruism is not evaluated as normative, people with high rejection avoidance may inhibit altruistic behavior in fear of possible negative evaluation from others.

Thus, individuals who tend to fear rejection from others may inhibit altruism, when altruism was not perceived as normative. However, as Kawamura and Kusumi (2018) did not directly manipulate social norms, this notion needs to be empirically investigated. In the present study, we conducted an online survey to investigate whether the relationship between reputational concern and altruism differed according to social norms. Participants read several vignettes depicting different scenarios, which either provided cues about a prosocial norm or a non-prosocial norm. We predicted that people with high rejection avoidance would inhibit altruism only in the context of non-prosocial norms. 


\subsection{Participants}

We recruited 320 Japanese participants (118 men and 202 women) online, aged between 20-29 years $(M=25.5, S D=2.85)$ via Crowdworks (a crowdsourcing service in Japan). Participants were randomly assigned to read vignettes containing either prosocial $(n=162)$ or non-prosocial norm $(n=158)$. Participants received 100 JPY for participation. This study was approved by the ethics committee of the institution with which the authors are affiliated.

\subsection{Measures}

\subsubsection{Praise Seeking and Rejection Avoidance Need Scales}

Two types of reputational concern were assessed using the 18-item Praise Seeking and Rejection Avoidance Need Scales (Kojima, Ohta, \& Sugawara, 2003; sample items were found in Kawamura \& Kusumi, 2018). Participants indicated the extent to which they agreed with statements on a five-point Likert scale $(1=$ false for me, $5=$ true for me). Higher mean scores represented higher levels of reputational concern.

\subsubsection{Vignettes}

Four short vignettes were created to measure participants' willingness to help a person in need. Each vignette had information about a social norm that was manipulated between groups. An example of one vignette:

$$
\text { room of the station. You noticed that one elderly person close to you was looking for }
$$
something lost. [Your friends also seem to have noticed that, and they were going to help 
112 the person looking for lost things (prosocial norm)] or [Although your friends also seem

113 to have noticed that, no one was going to help the person looking for lost things (non-

114 prosocial norm)]. When you are in such a situation, will you [also (prosocial norm)] help

115 to find lost things?"

116

Thus, the behavior of friends here reflects social norm manipulation. The other

vignettes included situations in which an elderly person was carrying luggage, picking up dropped coins, or picking up fallen bicycles (for details, see Supplementary Materials). These situations were adapted from the items of previous self-report altruism questionnaire (Oda et al., 2013). For each situation, participants rated the possibility that they would help the person (1: I will certainly not help, 7: I will certainly help). The responses were averaged and used as a measure of altruism (see Table 1 for $\alpha$ coefficients).

After answering the questions for each vignette, the sentence related to the norm manipulation was removed and participants were shown the vignettes again. Participants were asked to choose which sentence they previously saw: 1) prosocial norm sentence, 2) non-prosocial norm sentence, 3) unknown/do not remember. These questions were used as a manipulation check.

\subsection{Procedure}

Participants answered all questions using a computer. Participants first provided demographic information, and completed the Praise Seeking and Rejection Avoidance

134 Need Scale (Kojima et al., 2003) and Interpersonal Reactivity Scale (Davis, 1980; 135 translated Japanese by Himichi et al., 2017; see Supplementary Materials). Then, they 
136

137

138

139

140

141

142

143

read each of the four vignettes and rated their willingness to help. Finally, participants completed the manipulation check questions.

\section{Results}

Forty-six participants answered at least one manipulation check question incorrectly, choosing non-prosocial norm sentence when they actually read prosocial, or vice versa. Data from these participants were excluded from analyses. The final sample comprised 274 Japanese individuals (91 males and 183 females) aged 20-29 years $(M=$ $25.5, S D=2.81)$ who were exposed to either the prosocial norm $(n=150)$ or non-prosocial $\operatorname{norm}(n=124)$

Descriptive statistics per condition are shown in Table 1.

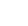

Hierarchical multiple regression analyses on altruism were conducted (Table 2). In Step 1, control variables, including age and sex, were entered. In Step 2, two types of reputational concern and a dummy variable of norm condition were entered. The independent variables explained a significant proportion of the variance in altruism $\left(F_{\Delta R^{2}}(3,268)=33.10, p<.001\right)$. The effect of norm was positive, indicating that individuals are more likely to help when a prosocial norm is present. We also found that the coefficient of praise seeking was significant, whereas that of rejection avoidance was not significant. Next, in Step 3, we entered interaction terms for the reputational concern and norm condition. The addition of interaction terms yielded a significant increase in explained variance $\left(F_{\Delta R^{2}}(2,266)=3.63, p=.028\right)$. As predicted, the interaction of rejection avoidance and norm was significant. Simple slope analyses revealed that 
160

161

162

rejection avoidance was negatively related to altruism in the context of non-prosocial norms $(B=-0.30,95 \% \mathrm{CI}=[-0.56,-0.04], \beta=.19, p=.022)$, but not prosocial norms $(B$ $=0.12,95 \% \mathrm{CI}=[-0.10,0.34], \beta=.07, p=.283 ;$ Figure 1$).$

As shown in Figure 1, many participants scored at the highest levels of the altruism variable; the ceiling effects were considered. Therefore, Tobit regression analyses were conducted on altruism. The results of the linear regression were replicated; the interaction of rejection avoidance and norm condition was significant $(B=0.51$, $95 \% \mathrm{CI}=[0.07,0.95], p=.022)$. Rejection avoidance was negatively related to altruism in the context of non-prosocial norms $(B=-0.38,95 \% \mathrm{CI}=[-0.71,-0.04], p=.027)$ but not prosocial norms $(B=-0.14,95 \% \mathrm{CI}=[-0.16,0.43], p=.363)$.

Hierarchical multiple regression analyses with empathic traits were also conducted as empathic traits are often related to altruism (Kawamura \& Kusumi, 2018). The results were mostly replicated except for that the coefficient of praise seeking was not significant (see Table S1, S2).

\section{Discussion}

The present study found that the relationship between rejection avoidance and altruism was moderated by social norms; that is, people who fear rejection from others tend to inhibit altruism only when altruism was not perceived as normative. These findings contribute to explaining the results of previous study (Kawamura \& Kusumi, 2018), which found that rejection avoidance is related to altruism toward strangers.

Our findings are in line with previous work showing that altruism can be negatively evaluated when it deviates from the social norm (Parks \& Stone, 2010). This 
may explain why people with high rejection avoidance display less altruism when nonprosocial norms are present. Although altruism generally leads to a good reputation (Barclay, 2012), people with high rejection avoidance may focus on the possibility that they will be negatively evaluated by others and subsequently refrain from altruistic behaviors when a prosocial norm does not exist.

Overall, the present study provides novel evidence that the relationship between altruism and rejection avoidance is moderated by social norms, and it provides a plausible explanation for the counterintuitive negative relationship between reputation and altruism. This result suggests the importance of considering the influence of social norms when investigating the relationship between reputation and altruism. However, there are several limitations. First, many participants scored at the highest levels of the altruism variable, indicating a possible ceiling effect was present. Even though the results of linear regression were replicated in Tobit regression analyses, future studies should focus on situations where a ceiling effect has not occurred. The second limitation concerns the generalizability of our results; as the sample was homogenous (all participants were Japanese and twenties). Future studies should try to replicate the study in more diverse samples. In addition, although the present study focused on altruism, it is worth investigating whether the relationship between rejection avoidance and social norms is found in different behaviors. Finally, and most importantly, the study arguably has poor ecological validity; as hypothetical vignettes and self-report measures were used. As it may not be easy for participants to imagine the situation in enough detail with the short vignettes, the effect size would likely be small. Indeed, a significant relationship between rejection avoidance and altruism was found only after controlling for other variables. 
208 Moreover, online data collection may have resulted in the high exclusion rate of

209 participants. Thus, it should be emphasized that our study did not investigated real

210 behavior and that such findings need to be replicated in more ecologically valid conditions.

211

212 


\section{References}

214

215

216

217

218

219

220

221

222

223

224

225

226

227

228

229

230

231

232

Andreoni, J., \& Petrie, R.(2004). Public goods experiments without confidentiality: a glimpse into fund-raising. Journal of Public Economics, 88, 1605-1623. doi:10.1016/s0047-2727(03)00040-9

Barclay, P.(2012). Harnessing the power of reputation: strengths and limits for promoting cooperative behaviors. Evolutionary Psychology, 10, 868-883. doi:10.1177/147470491201000509

Barclay, P., \& Willer, R.(2007). Partner choice creates competitive altruism in humans. Proceedings of the Royal Society B: Biological Sciences, 274, 749-753. doi:10.1098/rspb.2006.0209

Davis, M.H.(1980). A multidimensional approach to individual differences in empathy. JSAS Catalog of Selected Documents in Psychology, 10, 85-103.

Fehr, E., \& Fischbacher, U.(2003). The nature of human altruism. Nature, 425, 785-791. doi:10.1038/nature02043

Himichi,T., Osanai, H., Goto,T., Fujita, H., Kawamura,Y., Davis, M.H.,\& Nomura, M. (2017). Development of a Japanese version of the Interpersonal Reactivity Index. The Japanese Journal of Psychology, 88, 61-71. doi:10.4992/jjpsy.88.15218

Kawamura,Y., \& Kusumi,T.(2018). Relationships between two types of reputational concern and altruistic behavior in daily life. Personality and Individual Differences, 121, 19-24. doi:10.1016/j.paid.2017.09.003

Kojima,Y., Ohta, K., \& Sugawara, K.(2003). Praise seeking and rejection avoidance need scales: Development and examination of validity. The Japanese Journal of Personality, 11, 86-98. 
236 Lacetera, N., \& Macis, M.(2010). Social image concerns and prosocial behavior: Field evidence from a nonlinear incentive scheme. Journal of Economic Behavior \& Organization, 76, 225-237. doi:10.1016/j.jebo.2010.08.007

Oda, R., Dai, M., Niwa,Y., Ihobe, H., Kiyonari,T., Takeda, M.,\& Hiraishi, K.(2013). SelfReport Altruism Scale Distinguished by the Recipient (SRAS-DR): Validity and reliability. The Japanese Journal of Psychology, 84, 28-36. doi:10.4992/jjpsy.84.28

Parks,C.D.,\& Stone, A.B.(2010). The desire to expel unselfish members from the group. Journal of Personality and Social Psychology, 99, 303-310. doi: $10.1037 / \mathrm{a} 0018403$

Wu,J., Balliet,D.,\& Van Lange,P.A.M.(2016). Reputation, gossip, and human cooperation. Social and Personality Psychology Compass, 10, 350-364. doi:10.1111/spc3.12255 
Table 1. Means, standard deviations, coefficient alphas and correlations as a function of norm condition.

\begin{tabular}{|c|c|c|c|c|c|c|c|c|c|c|c|}
\hline & \multirow[b]{2}{*}{ Measure } & \multicolumn{2}{|c|}{ Prosocial } & \multicolumn{2}{|c|}{ Non-prosocial } & \multirow[b]{2}{*}{$\alpha$} & \multirow{2}{*}{\multicolumn{2}{|c|}{1.}} & \multirow{2}{*}{\multicolumn{2}{|c|}{2.}} & \multirow[b]{2}{*}{3.} \\
\hline & & $M$ & $S D$ & $M$ & $S D$ & & & & & & \\
\hline 1. & Praise Seeking & 2.82 & 0.78 & 2.83 & 0.76 & .85 & - & & .24 & $* *$ & .15 \\
\hline 2. & Rejection Avoidance & 3.47 & 0.81 & 3.57 & 0.73 & .85 & .05 & & - & & .15 \\
\hline 3. & Altruism & 6.28 & 0.89 & 5.06 & 1.28 & $.85^{\mathrm{a}} \% .86^{\mathrm{b}}$ & .22 & $*$ & -.16 & $\dagger$ & - \\
\hline
\end{tabular}

$\dagger p<.10 ; * p<.05 ; * * p<.01$. Intercorrelations for prosocial norm condition $(n=150)$ are presented above the diagonal, and intercorrelations for non-prosocial norm condition $(n=124)$ are presented below diagonal. ${ }^{\mathrm{a}} \alpha$ at prosocial norm condition. ${ }^{\mathrm{b}} \alpha$ at non-prosocial norm condition. 
Table 2. Hierarchical multiple linear regression predicting altruism from age, gender, norm condition, and reputational concern $(N=274)$.

\begin{tabular}{|c|c|c|c|c|c|c|c|c|c|c|c|c|}
\hline & \multicolumn{4}{|c|}{ Step1 } & \multicolumn{4}{|c|}{ Step2 } & \multicolumn{4}{|c|}{ Step3 } \\
\hline & $B$ & $95 \% \mathrm{CI}$ & $\beta$ & $p$ & $B$ & $95 \% \mathrm{CI}$ & $\beta$ & $p$ & $B$ & $95 \% \mathrm{CI}$ & $\beta$ & $p$ \\
\hline Intercept & 5.70 & {$[5.54,5.85]$} & & $<.001$ & 5.63 & {$[5.49,5.77]$} & & $<.001$ & 5.64 & {$[5.51,5.78]$} & & $<.001$ \\
\hline $\operatorname{Sex}^{\mathrm{a}}$ & 0.20 & {$[-0.11,0.52]$} & .08 & .211 & 0.26 & {$[-0.02,0.53]$} & .10 & .064 & 0.25 & {$[-0.02,0.52]$} & .09 & .072 \\
\hline Age & -0.02 & {$[-0.08,0.03]$} & -.06 & .361 & -0.01 & {$[-0.06,0.03]$} & -.03 & .581 & -0.01 & {$[-0.06,0.03]$} & -.03 & .569 \\
\hline Norm $^{b}$ & & & & & 1.22 & {$[0.96,1.48]$} & .49 & $<.001$ & 1.22 & {$[0.96,1.47]$} & .49 & $<.001$ \\
\hline Praise Seeking & & & & & 0.27 & {$[0.10,0.44]$} & .17 & .002 & 0.26 & {$[0.09,0.43]$} & .16 & .003 \\
\hline Rejection Avoidance & & & & & -0.07 & {$[-0.24,0.10]$} & -.04 & .443 & -0.09 & {$[-0.26,0.08]$} & -.06 & .289 \\
\hline PS $\times$ Norm & & & & & & & & & -0.23 & {$[-0.57,0.10]$} & -.07 & .169 \\
\hline RA $\times$ Norm & & & & & & & & & 0.42 & {$[0.09,0.76]$} & .13 & .014 \\
\hline$\Delta R^{2}$ & & & & & .27 & $* * *$ & & & .02 & $*$ & & \\
\hline$R^{2}$ & .01 & & & & .28 & $* * *$ & & & .30 & $* * *$ & & \\
\hline
\end{tabular}

${ }^{\mathrm{a}}$ male $=-0.5$, female $=0.5 .{ }^{\mathrm{b}}$ non-prosocial $=-0.5$, prosocial $=0.5$.

${ }^{*} p<.05 ; * * * p<.001 . \mathrm{CI}=$ confidence interval for $B$. Every continuous variable is centered. 
Figure 1. Scatter plot of altruism and rejection avoidance in each condition $(N=274)$.

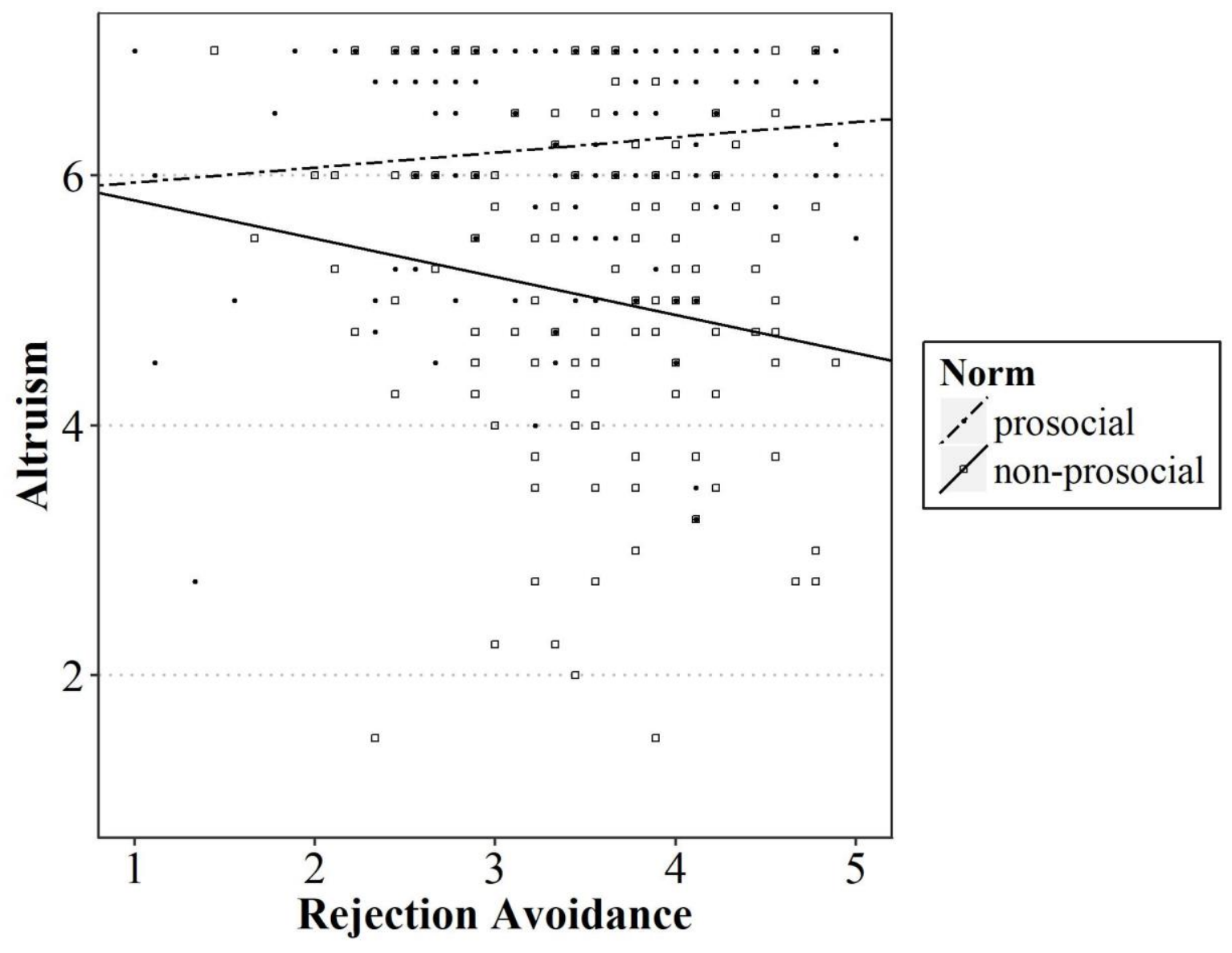

These regression lines are controlled for age, gender, and praise seeking. 